\title{
The Study of the Travelers' Ecological Appeal in the Innovation of Folk Tourism Product Xuxue Tan
}

Nanning College for Vocational Technology, Nanning, 530008, China

Keywords: Folk tourism, Ecological needs, Folk culture

\begin{abstract}
At present, people concern more about their physical and mental health, health maintenance and the spiritual level when their material needs have been fully satisfied, which is enlightened by the green and ecological health of the modern thought. They begin the pursuit of the most original and natural condition. For travelers, the most important and valuable is that it reveals the original and authentic folk tourism. This text will analyze the travelers' ecological needs of folk tourism according to the travelers' perception problems about travelling products in folk tourism and discuss the development of folk tourism resource in our country by taking the development of the travelling in Xiangxi as an example.

For folk travelers, they have their own unique value appeals. The appeal on the first level shows up as the casual attitude toward the experience of the folk-custom taste, the hunt for novelty and life and the feelings of national customs. It is the aspect which interests the folk travelers the most; the appeal on the second level manifests as the interactive experience among the folk cultures, the sense of alienation toward the cities, the appreciation of the most original natural scenery, the taste of the authenticity and the food. This aspect is still underdeveloped and ignored, but it is the travelers' value point with huge market potential; the appeal on the third level performs as the expectation of romantic love, the materials and truly depiction of artistic creation and an adventurous experience of natural scenery. This appeal stands out for some visiting groups and it is a breakthrough point for the construction of differentiating factors in the scenic spot. At the same time, a large amount of travelers show special preference for the ornaments with national features, handmade articles and national specialty. This is the appeal on the fourth level which is a complementary appeal that makes the travelers' travelling intact.
\end{abstract}

\section{The Introduction of the Problem}

Early in the 1840s, some scholars who have conducted the field research in some Southeast Asian countries put forward that folk culture plays a vital role in the tourism development in the Southeast Asian countries. Later, some scholars proceeded a more in-depth study about the patterns of tourism development in the multinational residential areas of the Southwest region in our country by taking China as the object study and from the scientific and professional perspective of cultural geography. They pointed out that at present, there exist strong political goal, too much intervention and limitation in tourism development. This aspect should be weakened and restricted. We should attach more importance on the factors of social development and consider it as a crucial aspect so as to play its critical role. In our country, some scholars have publicized a series of thesis of scientific research in succession from 2008 to 2012. Taking the Xishuangbanna folk tourism as an example, from the different angles of view such as local governments, tour operators, office clerk and travelers, it reveals the combination of national customs exhibition and ethnic elements contained in the development project of the distinctive national tourism through the exhibition of the national cultural tourism existed in the folk tourism villages in Yunnan province which locates in the 
southwest of China. At the same time, they also make a detailed discussion about the development of the featured products in ethnic folk tourism, the reasonable plan of the scenic spot and management problems. However, how to combine the folk tourism product with national features and the value appeal of the travelers perfectly is still a new topic which needs through study.

As is known to all, the Xiangxi natural scenery which is unique, beautiful and fertile creates a big eco-cultural tourism circle in Xiangxi itself, which also provides a solid foundation for the tourism development in Xiangxi. The strong characteristics with national customs and the beautiful landscapes are the two key engines in the area. In Xiangxi's ethnic enclaves which are multiracial and multicultural, the folk resources is also quite rich and unique. It makes folk tourism the crux and a must of the tourism industry development in this area. In 2011, Hunan province made the increase of the construction of an eco-cultural tourism economic belt in Xiangxi as the major goal of the 12th five-year plan, so it offered a brand-new opportunity for the cultural tourism in Xiangxi. It also indicated that the Xiangxi folk culture would develop further with higher innovation. However, at the same time, how to design the folk products with characteristic aiming at the value demand of the travelers with the nature and cultural customs combining perfectly was a factor that needs focused study. Moreover, a range of successful entertainment works with the Xiangxi tourism being the theme also provides us the field experience and defines the direction of the development of innovative folk culture. They open up a new mode of folk tourism in which the natural scenery and the cultural customs promote one another, so it can better cater for the appeal of different travelers about the value of various folk tourism. In this way, the travelers can really enjoy the mixed pleasure of spirit and culture.

\section{II .The Discussion of the Folk Travelers' Ecological Tourism Needs}

With more and more people influenced by the cultural root-seeking in the revival thought of the original socialism, the pursuit of the original and natural ecology becomes a prominent value demand in folk tourism. People long for the isolation from the big cities they are used to live and the experience of the different, original, natural and authentic national culture in a remote place. It makes folk tourism especially characteristic and important under the drive of the needs.

(1). The Basic Demand of the Travelers is the Original and Natural Cultural Ecology

The factor that the travelers consider the first is the natural and original cultural form with national geographic features. If it cannot meet the tourism value needs of the travelers, then they will fell unsatisfactory. Also we take Xiangxi as an example. The ecological needs of folk tourism culture should possess the following elements:

1. The Unique National Cultural

When we refer to Xiangxi, it is most likely for the people to associate it with the words such as soil temple, Nuo god, Miao drum, Yashu, because obviously, these words have become the synonym of Xiangxi tourism culture, also the embodiment of Xiangxi national culture and the key for us to study the vein and spirit of humanity history in west Hunan. We can say that the folk culture has taken root in this area, Xiangxi and gestated generations of Xiangxi people from the source. The folk culture exists in their bone and thoughts. Filling with the feelings of cultural root-seeking, the folk travelers are eager to be edified by the Xiangxi folk culture with unique characteristics and understand more about the peculiar minorities in this genuine and original cultural belief.

2. The Original and Authentic Nations Celebrate the Holidays

The traditional national holiday is an indispensable part of the national culture. The folk sing in antiphonal style of the young and pretty girls and boys in Xiangxi on the Valentine's Day stirs our 
good desire and romantic memory for love; the solemn and respectful memorials for the heroes on the Hero Day make us feel the perfect heritage of the past history on the characteristic national holidays; During the harvest season in autumn, we understand that content is better than riches and the satisfaction gained by there are gains to pay through the heartfelt joy of harvest......Xiangxi people repose their emotions by celebrating different holidays and if the travelers experience it, they will feel it buried in their heart. The most original celebrations of the holiday is the regression appeal that the travelers pursue.

3. The Characteristic National Specialty

Passed on by history, the hand-made national exquisite costumes, various folk craft exhibits, healthy and delicious food with characteristics and all kinds of legend about Xiangxi are all extracted from nature, made attentively with no deliberate trace of decoration from machine process or obvious polishing by machines. Thus people can intuitively taste the pleasant sensation of manual creation, which accords with the ecological needs of the specialty in folk tourism sent from the travelers.

\section{Self-created Dance}

Represented by the waving dance in Xiangxi, all the dances manifest the description which is as high as art toward life; it mainly reveals its pursuit toward the original culture; the dances make the parting and passion in life as one and one touching folk music to repose people's emotions..... The folk travelers start to appreciate the level and height of the national culture from the pure enjoy of the national singing and dancing to taste and aftertaste it slowly.

(2). The Potential Needs of the Folk Travelers Manifest as the Green and Healthy Natural Ecology

In folk tourism, it is easy for the travelers to ignore the natural ecology and pursue the national culture blindly without knowing that the formation and authenticity of national cultural background lie in an equally important position with the uniformity of natural scenery and cultural context. When the travelers are appreciating the original and characteristic national culture, they also yearn for the natural and original beautiful scenery and hope that the two can combine perfectly and influence each other in harmony. Once the potential needs of the travelers are satisfied well, then the satisfaction of the travelers will be inspired. Needless to say, the natural scenery in Xiang areas is abundant, so the combination of original scenery and natural cultural should be considered while pushing the folk tourism to make the travelers feel the double beauty of nature and culture. Grasping this point is also the reason for the success of some movies with tourism theme in some degree.

(3). The Construction of the Appealing Model of the Folk Ecological Travelers

According to the opinions pointed by the scholars, dissatisfaction is the opposite side of satisfaction. In turn, no dissatisfaction is the opposite side of dissatisfaction. If we take out dissatisfaction, then we can only get the result of dissatisfaction, which make people feel satisfied. If this is applied to the ecological appeal of the travelers in folk tourism, then the satisfaction in humanity ecology can only dissatisfy the travelers while if the original natural ecological environment is merged into the travelers' natural cultural experience, then travelers will get new promotion in their satisfaction index and sublimation of their emotions, and finally feel satisfied.

\section{The Development Strategy and Content of the Folk Tourism in Xiangxi}

(1). The Development Strategy

Taking advantage of the characteristics of abundant natural scenery, diverse national culture and the minority inhabitation in Xiangxi area, people should abandon the category of forging cultural 
tourism alone and mould the independent and characteristic folk tourism mode. Firstly, they should make the local national culture with unique characteristics as the core content to create the brand of folk tourism, give priority to the dynamic culture such as showing national singing and dancing, the convention in national holidays and the handcraft design of the handiwork and consider the static change of natural scenery as the secondary cause to make the travelers merge fully into the unique atmosphere of cultural scenery in Xiangxi. The second one is to take advantage of the landscaping with the natural scenery being the background and the launch of the products. In this aspect, the match and harmony of natural scenery is required on one hand and the national cultural deposits and the landscape should be merged as a whole in harmony through specific expression on the other hand.

(2). The Development Contents

The ecological needs about the folk culture emphasized by the travelers, the unique and mysterious Wunuo culture, various customs of national holidays, the distinctive cooking culture, the singing and dancing of the colorful minorities, the elegant folk craft, etc in Xiangxi area play a vital role in the development of Xiangxi folk tourism, so they should be utilized and taken into consideration. At the same time, the gorgeous grand canyon formed by the distinct geography in Xiangxi and the beautiful peak which looks like a fairyland with the fog around is also a wonder. It can be used together with the brand culture in Xiangxi with the goal of reach the harmonious combination of the two.

\section{The Model Construction of the Value Factor Matrix of the Folk Travelers}

The innovative value factor matrix of the clients in the folk tourism products regards most tourism market in Xiangxi as the study basis. After the 12 strongest demand point of value in the tourism market is screened, then they are conducted a comprehensive analysis and discussion with the resource character of the folk tourism. At last, a model is constructed and formed.

Different folk travelers have different needs, which leads to the travelers' multiple sense of depth on value demand. With this understanding, the individual should be given into serious consideration in the development study of the folk tourism mode in order to accord with the different value demand of the travelers.

According to the different strength, factor matrix is divided into four quadrant, I, II, III and IV, which represent the 4 degrees of value factors respectively. In line with the travelers' appeal and their different emphasis toward the resource character, the four degrees correspond with the appeal on the first, second, third and fourth level discussed earlier in this text. For the development of folk tourism, the first quadrant should be concerned in the first place because the strength of value demand is big. Secondly, it turns to the second and the third quadrant which should be exploited due to their own emphasis. At last, as to the fourth quadrant, although it's a complementary appeal, it should be given enough study and investigation and then be further developed innovatively.

What I want to emphasize here is that as vertical ordinate is the character of the resource, then it makes the combination of convenience and the quality products with cheap prices not so reliable for the travelers. Therefore, it seems that there is still slant less about the travelers' value expression about function. Horizontal and vertical ordinate have 96 junctions. For other junctions, everyone thinks in its own way in the opinion of the scholars.

\section{Conclusion}

According to what we have discussed before, we can see that as a kind of humanity resource, the 
folk tourism resource with its own and extreme uniqueness bears the humanity cultural context of an area and embodies people's emotional sustenance and belief in some regions. It plays an important role in the national tourism development in the future and must be taken into serious consideration. The value factor matrix model of the folk travelers listed in this text also shows clearly the different functions of the demand strength and resource character in folk tourism, which provides a brand-new thought for the development of folk tourism and the innovation of folk tourism products.

\section{References}

[1]Chengting, Huangwei, Zhang Tingting. The Study of Travelers' Ecological Appeal in the Innovation of Folk Tourism Product-Taking Xiangxi as an Example. Guide to Business, 2012,07:146-147.

[2] Huangwei, Chengting, Wangli. The Study of the Clients' Value Demand in the Innovation of Folk Tourism Product-Taking Xiangxi Autonomous Prefecture as an example[J]. Tourism Tribune, 2013,12:64-70.

[3] Maliang, Chengge, Huangkai, Yan Tingyu. The Innovation System Analysis of the Folk Tourism Products in Suburban areas of Beijing[J]. Chinese Agricultural Science Bulletin, 2011,08:479-482

[4] Zhang Xueting. The Development and Research Based on the Travelers' Experience about the Folk Tourism Products in the Minority Areas[D]. Hunan Normal University,2009.

[5] Wanglei. The Innovative Study about the Folk Tourism Products of the Korean Nationality in Yanbian, Jilin province[D].Guangxi University, 2013. 